\title{
Research on Training Mode Based on Production, Education and Researching with Occupation Ability Promotion
}

\author{
Zhi-Yu ZHOU ${ }^{1, a,{ }^{*}}$, Di-Chong WU ${ }^{2, b}$, Feng FU ${ }^{1}$, Jing SUN ${ }^{1}$ \\ ${ }^{1}$ College of Information, Zhejiang Sci-Tech University, Hangzhou, Zhejiang, 310018, China \\ ${ }^{2}$ Business Administration College, Zhejiang University of Finance \& Economics, Hangzhou, Zhejiang, \\ 310018, China \\ azhouzhiyu1993@163.com, ${ }^{\mathrm{b}} 1601441815 @ q q . c o m$ \\ ${ }^{*}$ Corresponding author
}

Keywords: Combination of production, Education and researching, Occupation ability, Professional degree of postgraduate, Training mode.

\begin{abstract}
In order to make the professional degree postgraduate more adapted to the developments of economic and society, we make a research on the training mode of professional degree postgraduate based on combination of production, education \& researching and occupation ability promotion. In the process of strengthening the professional degree graduate training, we proposed to strengthen substantive docking between enterprise teacher and college teacher, striving for support of government and enterprise. We should strengthen on the study of practice effects of education, construct the collaborative innovated postgraduate cultivating mechanism combined with producing, education and researching and improve the occupation oriented postgraduate cultivating mode, so that we can improve the professional degree postgraduate's practice and application ability, as well as promote the innovation ability while solving the practical engineering problems.
\end{abstract}

\section{Introduction}

To meet the development of economic and social, China's postgraduate education structure added the professional degree postgraduate education to adjustment the change. Training mode of professional degree of postgraduate becomes a hot topic in the field of education research. Wang Lidong [1] starting with the current situation of education which the postgraduate students received in the teaching-research type universities, analyzed postgraduate training mode and existing problems in the cultivating process, proposed the practice of school enterprise cooperation platform and segmented training, created a new way of cultivating postgraduate combing with producing, educating and researching. Huang Weihua [2] proposed to take the market demand as the guidance, emphasis the training target difference between practice type and occupation type. Taking the combination of producing, educating and researching an opportunity, strengthen construction of practice base and actively implement the "Dual Teacher" model and other full-time professional degree graduate cultivating mode. Chen Wen [3] proposed to changes in personnel training concept of stakeholders that the cultivating target must reflect the demand of society and the curriculum must meet the objects' requirement. The corresponding department participate the cultivating process and equality evaluation, establish and perfect the internal operating mechanism and external safeguard mechanism of postgraduate cultivating model. Only in this way, can the combination of producing, educating and searching postgraduate cultivating model operate and develop in a relatively stable and long-term efficient way. Zhao Ke [4] put forward the platform of teaching, innovation mode from the curriculum construction and the combination of producing, educating and searching practice base construction and other aspects of graduate education strengthen the training of graduate students' practice ability, develop scientific research and innovation ability in the innovation practice. Jiang Zhisheng [5] points out that the construction of innovation base is an important practice of cultivating graduate student innovation ability, combining with the construction situation of "overview of the construction of innovation base" in the University of South China, explored a postgraduate training mode based on "innovation base" which combined with producing, educating and searching. Wei 
Hong [6] focus on the present graduate education problems of insufficient funds and the unitary training model, by using questionnaire, mathematical statistics and other research methods, using questionnaire, mathematical statistics and other research methods, put forward that let senior technical staff of enterprises' technology center to participate in the graduate cultivating process is a good way to promote the innovating graduate cultivating.

After reading a great many paper, cooperating with the relevant enterprises in the transverse project, our group study on the professional degree graduate training model based on combining of producing, educating and researching and occupation ability promotion.

\section{Professional Degree Graduate Training Model Researching}

It is the key point of postgraduate education reform in the new period for our school, ZheJiang Sci-Tech University that deepen the reform of professional degree postgraduate training mode, improve the professional degree postgraduate quality, cultivate high level applied talents who have good occupation attainment and ability. In this paper, we aim at professional degree graduate cultivation target, take occupation demand as a guidance, emphasis practice ability cultivating, get the way by combining producing, educating and researching. We have constructed the professional degree postgraduate cultivating model which can meet the requirement of economic society, reflect the feature and advantage of our school, improve the quality of professional degree postgraduate.

In order to research the cultivating model of professional degree which practice and application property are highly demanded, we investigate professional degree postgraduate's cultivating of several university in Hangzhou, e.g. Zhejiang University, Zhejiang University of Technology, Electronic University of Science \& Technology of Hangzhou, Commerce of Zhejiang University. We adopt other university's advanced educating concept and management method and propose the cultivating model of professional degree of postgraduate based on combination of production, education \& researching and occupation ability promotion which can appropriately solve the existed problem that cultivating model lays a particular bias on theory study and lack innovation \& practice ability training.

\section{Strengthen substantive docking between enterprise teacher and college teacher}

Collaborating undertake the cultivating of professional degree postgraduate with various experts, scholars and professional personal in their own field. We need encourage enterprise tutors' enthusiasm in the establishment process, which requires company's attention and its policy orientation, meanwhile strengthen the corporation between school and enterprise, enhance substantive docking between enterprise teacher and college teacher. The exploration and utilization of enterprise tutor resource is not only a good condition for cultivating full time professional master, but also benefit for companies to promote innovating ability and contribute to university teachers to know about technology demand and to accumulate practice experience. It is a good way for the tutor of master to participate in the particular project and to solve physical problems in the producing process, which make our teacher know clearly about society's needs for graduate, thus we can find a great many work availability in the cooperation with enterprise.

\section{Striving for support of government and enterprise to strengthen on the study of practice base's effects on education}

It is essential obtain both solid theoretical knowledge and stable project practice ability for senior dynamic apply-oriented talents. This requires the teacher not only undertake the tasks of teaching in schools, but also complete research projects and engineering cooperating with enterprises, teach the theoretical knowledge combined with practical application, schools should strive for government and enterprises' support for establishing united postgraduate training base, construct a long-term comprehensive cooperation between school and enterprise. It is helpful for professional graduate to expand horizon, enhance working ability and professional quality. That is also a win-win process to both school and enterprise, for which takes part in the cooperation would increase the innovation ability for school's education and enhance competitive strengthen. 
Strengthen cooperation between universities and related enterprises in scientific research and resources sharing can improve resource utilization rate and the personnel training benefit. Schools take enterprises' participation and enthusiasm into consideration can cultivate customized apply-oriented graduate for the company, which markedly increase enterprises' participation and satisfaction, benefit for enterprises' upgrading and reforming, enhance enterprises' competition. Therefore, strive for government and enterprises' support; build a number of high standards of postgraduate innovative education demonstration practice base is intrinsic to the cultivation of professional degree graduate.

During the practical research process, we construct cultivating base cooperating with several companies, e.g. HangZhou WSeen Detection Technology Co.,Ltd., Hangzhou Beilaifu Automation Engineering Equipment Co. Ltd., Hangzhou Wolin Technology Co., Ltd., Chengdu Qun Yi Food Co. Ltd., Zhejiang Fanping Textile Co., Ltd., Hangzhou online Liancheng Technology Co. Ltd., Shanghai Fanhong Building Materials Co., Ltd., in developing electronic commerce system of food enterprise, control system of gearbox test bench, marketing management system of energy-saving materials, production management system of textile enterprises, information system of building material industry and Intelligent video surveillance system. By participating the developing process, our graduate can enhance their innovation and practice ability.

\section{Construct cooperative mechanism of innovation platform}

By giving full play to their respective advantages of universities, enterprises and scientific research institute, cooperative combing basic study, technology research and graduate cultivating, we appropriately eliminated the gap between professional degree graduate and enterprises' real technology demand. Cooperative innovation cultivating system based on project collaboration, we integrate teaching, academic, technology, equipment and various high quality resource and adjust the curriculum according to graduate cultivating characteristic. Taking relevant research projects as a link, we combine the professional team of graduate students together, cooperating, researching. Through this research cooperation and mechanism of team study we can greatly stimulate professional graduates' innovative thinking. We construct the study team around teacher surround with graduate, thus we can cultivate collaborative and creative capability by solving the problems we encountered in the projects.

We have started the cooperation postgraduate training model and realized school and enterprises' cooperation. Combining with discipline closely related enterprises, we research on institutions to establish innovation base for graduate students, and thus graduate research can be directly involved in the project in practice base. We conduct an all-round cooperation between graduates' tutor, research institution and other relevant institutions, thus the postgraduates' practice and application capability was highly promoted.

\section{Research on training mode of professional degree of graduate based on occupation ability promotion}

Under the background of requirement of practice and the occupation differentiation cultivation mode, universities should cultivate senior apply-oriented talents which can meet market's demand by combining with producing, educating and researching, constructing of practice base and double-tutor mechanism. Higher education of professional degree requires distinctive practicability, which means that the man who obtains a professional degree should have high level of theory and practical ability to apply the theory as well. Modern technology is a composite of high occupation technology based on intelligent technology. People must solve the high technical content of work by accepting higher education. Professional degree is often engaged in occupation post corresponding to the high level of the industry, so we need formulate scheme according to the professional characteristics, the needs of the society and the local characteristics. We must pay attention to the law of development of relevant professional, tracking and thorough researching advanced science and technology innovation, launching reform measures to deal with the emergence. In addition, the strengthening of international cooperation and exchanging to the professional degree education is essential, so as to establish a professional degree study which enhance the professional ability oriented growth guarantee system. 


\section{Summary}

It has great significant meaning of developing full-time professional degree graduates' training model for the optimization and adjustment of China's graduate education structure and social development. The cooperation and to promote the occupation ability for the purpose of full-time professional degree graduate innovative ability training based on combination of producing, educating and researching and occupation capability promotion is a kind of practical education model which integrates theory study and experiment and aims at improving graduates' innovation and practice capability. In order to adapt to economic and social development and progress of science and technology, combining the training of full-time professional degree graduate innovative ability is the inevitable choice for China's higher education reform in Colleges and universities as well as its own development. Occupation differentiation is the inherent motive force of the development of higher education of professional degree. It must be solved by high level of education. Occupation, practice and application is the characteristics of professional degree talents' cultivating, they are closely associated with these features and modern high-tech occupation, so research on the training mode of professional degree of postgraduate based on combination of production, education $\&$ researching and occupation ability promotion has its significant meaning.

\section{Acknowledgement}

This research was financially supported by the postgraduate research project of education and teaching reform of Zhejiang Sci-Tech University (YJG-Z14001) and the postgraduate research project of education and teaching reform of Institute of information (Information policy No. [2014] $15)$.

\section{References}

[1] Wang Lidong, Wang Xiaoyu, Chen Xuebo, et al. Study on cultivation mode of application-oriented postgraduate students. Journal of University of Science and Technology Liaoning, 2014, 37(3): 319-322.

[2] Huang Weihua, Liu Bin, Zhang Zheng. Investigation on the training model of full-time professional master's programs in view of employment demand, Journal of Graduate Education, 2014, 23(5): 63-67.

[3] Chen Wen, Peng Wen, Peng Yong. Analysis for Development in Cultivating Model of the University Industry Cooperation- From the Perspective of Stakeholder Theory, Journal of Guangxi Normal University(Philosophy and Social Sciences Edition), 2013, 49(2): 144-148.

[4] Zhao Ke, Jia Jie, Fang Fang. Research and practice of training mode of postgraduate's practice and innovation ability. Journal of Wuhan University (Natural Science Edition), 2012, 58(s1): 201-203.

[5] Jiang Zhisheng, Xin Yan, Yuan Zhonghua, et al. A research on educational mechanism of combining industry-university innovation base for postgraduate training. Journal of Hunan University of Science and Engineering, 2012, 33(12): 147-148.

[6] Wei Hong,Ding Yuehua,Li Junji. On cultivation mode of postgraduates based on integration of production, study and research. Social Sciences Journal of Universities in Shanxi, 2010, 22(4): 114-116. 